\title{
Mini-review: The role of mast cells in pulmonary hypertension

\author{
Yijie $\mathrm{Hu}^{1,2}$, Wolfgang M. Kuebler $1,3,4$
} \\ 'Keenan Research Centre for Biomedical Science, St. Michael's Hospital, Toronto, ON, Canada \\ ${ }^{2}$ Department of Cardiovascular Surgery, Institute of Surgical Research, Daping Hospital, Third Military Medical University, Chongqing, China ${ }^{3}$ Departments of Surgery and Physiology, University of Toronto, Toronto, ON, Canada ${ }^{4}$ Institute of Physiology, Charité Universitätsmedizin Berlin, Berlin, Germany
}

Article Info

\section{Article Notes}

Received: October 07, 2017

Accepted: November 28, 2017

\section{${ }^{*}$ Correspondence:}

Prof. Wolfgang M. Kuebler,

Institute of Physiology, Charité - Universitätsmedizin Berlin

Charitéplatz 110117 Berlin, Germany, Telephone: +49 (0)30

450528 501; Fax: +49 (0)30 450528 920;

Email: wolfgang.kuebler@charite.de

(c) 2017 Kuebler WM. This article is distributed under the terms of the Creative Commons Attribution 4.0 International License.

\section{Keywords}

Pulmonary hypertension,

Immune response,

Mast cells,

Bronchus-associated lymphoid tissue,

IL-6

\section{ABSTRACT}

Of recent, inflammatory responses, formation of ectopic lymphoid tissue and autoantibodies have been increasingly implicated in the pathophysiology of pulmonary hypertension ( $\mathrm{PH})$. One of the earliest immune cells detected in $\mathrm{PH}$ and implicated in its pathogenesis were mast cells based on their demonstrated abundance in the vicinity of vascular lesions in $\mathrm{PH}$ patients, as well as in lungs of animal models of PH. Experimental studies using mast cell stabilizers or mast cell deficient rats in classic $\mathrm{PH}$ models provided proofof-principle for the functional relevance of mast cells in the initiation and/or progression of $\mathrm{PH}$ and lung vascular remodeling. Yet, the cellular mechanisms by which mast cells contribute to the development of $\mathrm{PH}$ and pulmonary vascular remodeling have so far remained largely unclear. Importantly, understanding the downstream effectors by which activated mast cells and their secretome trigger or promote vascular remodeling may lead to the development of novel therapies for PH. Notably, recent work has unveiled a novel interplay between mast cells and the adaptive immune system in $\mathrm{PH}$, in that mast cell-targeted interventions attenuate the formation of tertiary lymphoid tissue in the lung and the formation of autoantibodies. This minireview will focus on the role of mast cells in $\mathrm{PH}$ and their possible downstream mechanism.

Pulmonary hypertension (PH) is a devastating vascular disease characterized by remodeling of the small pulmonary arteries, elevated pulmonary artery pressure, and subsequent development of right heat failure. The clinical introduction of endothelin receptor antagonists, phosphodiesterase 5 inhibitors, and prostacyclin or its analogues for the treatment of pulmonary arterial hypertension has generated sustained patient benefits in hemodynamic function, exercise capacity, and longevity. Yet, while single and combination therapies have doubled survival rates for PAH since the 1980s, the current overall 5-year survival remains abysmal at approximately $60 \%{ }^{1}$. Other forms of pulmonary hypertension $(\mathrm{PH})$ such as $\mathrm{PH}$ due to left heart disease (class 2), PH due to lung diseases and/or hypoxia (class 3), or chronic thromboembolic PH (class 4) have even less (soluble guanylate cyclase inhibition by riociguat in class $4 \mathrm{PH}$ ) or no (class $2 \& 3 \mathrm{PH}$ ) approved treatment strategies, stressing a large unmet need for new and better therapeutic targets ${ }^{2}$. Over the past decades, an accumulating body of studies have highlighted a possible role of inflammation and immunity in the development of the disease. First it was noticed that specific autoimmune diseases or inflammatory conditions, such as connective tissue diseases or HIV infection, were associated with an increased incidence of $\mathrm{PH}^{3,4}$. Histological analyses of lung biopsies revealed an abundance 
of various immune cells around the vascular lesions. Specifically, macrophages, mast cells, $\mathrm{T}$ lymphocytes, and B lymphocytes were found to accumulate not only in patients with underlying autoimmune diseases or infections, but similarly in different forms of pulmonary arterial hypertension $(\mathrm{PAH})^{5,6}$. In line with the notion that $\mathrm{PH}$ may be associated with an inflammatory/ immune response in the pulmonary vasculature, high levels of pro-inflammatory cytokines as well as various autoantibodies were confirmed in animal models and patients with pulmonary hypertension ${ }^{7}$. In support of a potential mechanistic contribution of inflammation and autoimmunity in $\mathrm{PH}$ disease, perivascular inflammation was found to correlate with the severity of pulmonary hemodynamics, vascular remodeling, and worse clinical outcomes ${ }^{8}$. Conversely, immuno-targeted therapies have demonstrated beneficial effects in animal PAH models and some human PAH subtypes associated with marked inflammation ${ }^{9}$.

Of the various immune cells that have been implicated in PH disease, mast cells were among the first to be recognized and suggested to potentially play an important role in the pathophysiology of pulmonary hypertension. As early as in 1879, Paul Ehrlich noted that mast cells were abundant in "brown induration of the lung", i.e. in hemosiderosis following mitral stenosis ${ }^{10}$-a disease which would nowadays be classified as pulmonary hypertension secondary to left heart disease. Since then, pathologic studies have confirmed an accumulation of mast cells in lungs of patients with PH secondary to congenital cardiac septal defects or mitral stenosis as well as in patients with idiopathic $\mathrm{PH}^{11-13}$. Similarly, the number of mast cells and mast cell-related protein expression was found to be significantly increased in the lungs of patients with congenital heart disease associated with early pulmonary vascular disease $\mathrm{e}^{14,15}$. These clinical findings were paralleled by reports of similar mast cell accumulations in experimental $\mathrm{PH}^{16-19}$. Gene array analysis and subsequent RT-PCR confirmed that several genes associated with the proliferation and presence of mast cells were induced in monocrotaline (MCT)-induced $\mathrm{PAH}^{20}$. Similarly, the gene ontology class with the most pronounced differential regulation was the class "mast cell activation" in a rat model of left heart disease (LHD)-induced PH subsequent to aortic banding ${ }^{21}$. Although these studies cohesively proposed an important role for mast cells in $\mathrm{PH}$, until recently this hypothesis had never been experimentally tested.

Over the pastyears, a series of independent experimental studies have provided proof-of-principle evidence for a critical role of mast cells in pulmonary hypertension and lung vascular remodeling. Mast cell deficient $W s / W s$ rats, in which mutations in the mast cell growth factor receptor c-kit inhibit maturation, differentiation, activation and migration of mast cells ${ }^{22}$, develop less $\mathrm{PH}$, lung vascular remodeling, and right ventricular hypertrophy in response to MCT. Inhibition of mast cell degranulation by so called mast cell stabilizers similarly reduced the development of MCT-, hypoxia- or LHD-induced PH and lung vascular remodeling dramatically ${ }^{21,23-25}$. A potential role of mast cells in human PH disease was also indicated by a small clinical trial in 9 patients treated with the mast cell inhibitors cromolyn and fexofenadine for 12 weeks, which resulted in a drop in vascular endothelial growth factor (VEGF) and circulating proangiogenic $\mathrm{CD} 34^{+} \mathrm{CD} 133^{+}$progenitor cells, and an increase in exhaled nitric oxide ${ }^{26}$. Although these findings strongly indicate a role of mast cell in pulmonary hypertension, the underlying mechanism was yet not understood.

Two main proteases from mast cells, chymase and tryptase were reported to increase and correlate with severity of pulmonary hypertension and pulmonary vascular remodelling ${ }^{13,14,27-30}$. In clinical trials, Imatinib, a tyrosine kinase inhibitor targeting c-Kit, was shown to decrease both total tryptase and pulmonary vascular resistance, suggesting c-Kit inhibition as a potential mechanism of action of imatinib in PAH and tryptase as a potential biomarker of response to therapy ${ }^{31}$. In addition, tryptase may also be of direct mechanistic relevance in $\mathrm{PH}$, as tryptase was shown to induce pulmonary artery smooth muscle cell proliferation and migration as well as synthesis of fibronectin and matrix metalloproteinase- 2 in a proteaseactivated receptor (PAR)-2- and extracellular signalregulated kinase (ERK) 1/2-dependent manner ${ }^{32}$. Similar to tryptase, mast cell chymase has been mechanistically implicated in the pathogenesis of $\mathrm{PH}$, specifically in the context of lung fibrosis. In a model of bleomycin-induced $\mathrm{PH}$, chymase inhibition attenuated the development of both $\mathrm{PH}$ and pulmonary fibrosis, presumably via reducing transforming growth factor- $\beta 1$ (TGF- $\beta 1$ ) and matrixmetalloproteinase-2 (MMP-2) contents in the lungs ${ }^{28}$. Chymase also processes pro-matrix metalloprotease 9 (pro-MMP-9) to active MMP- $9^{33}$ which is a biomarker for scleroderma-associated $\mathrm{PH}^{34}$.

In addition to releasing preformed enzymes such as tryptase or chymase or biogenic amines like histamine or serotonin from their intracellular granules ${ }^{35}$, mast cells also de novo synthesize and secrete mediators which may similarly contribute to the induction and/or progression of $\mathrm{PH}$. Of late, formation of bronchus-associated tertiary lymphoid tissue (BALT), which had initially been reported as a classic hallmark in chronic inflammatory lung disorders and autoimmune diseases, was identified in lungs of IPAH patients and PAH animal models and has been proposed to play an important role in disease progression ${ }^{36}$ since diminution of tertiary lymphoid tissue reversed $\mathrm{PH}$ and pulmonary vascular remodeling in experimental $\mathrm{PH}^{37}$. 
Notably, c-Kit ${ }^{+}$cells with a typical mast cell phenotype expressing FceRIa and tryptase were found to localize around BALT, suggesting that mast cells may potentially promote lymphoid structure development ${ }^{36}$.

Indeed, mast cells can secrete large amounts of immunomodulatory compounds which may potentially regulate the formation of BALT in PH. In a recent study, we showed that mast cells recruit and activate B cells via the release of interleukin- 6 (IL-6), thereby promoting the formation of tertiary lymphoid tissue and the production of autoantibodies, which in turn accelerated the progression of $\mathrm{PH}$ and pulmonary vascular remodeling ${ }^{38}$. Accordingly, mast cell stabilization as well as B cell depletion by an antiCD20 antibody or IL-6 neutralization improved PH and reduced pulmonary vascular remodeling in experimental models of $\mathrm{PAH}^{38}$. The emerging relevance of an IL-6mediated mast cell - B cell axis in $\mathrm{PH}$ is in line with the high predictive value of elevated IL-6 plasma levels in $\mathrm{PAH}$ patients ${ }^{39}$ and the demonstrated pathophysiological role of this cytokine in animal models of $\mathrm{PH}^{40,41}$. Originally identified as a B cell stimulatory factor that induces differentiation into antibody-producing plasma cells ${ }^{42}$, IL-6 production has also been linked to increased Ig secretion and production of autoantibodies ${ }^{43}$. Of relevance to the proposed mast cell - B cell axis in PH, IL-6 release from mast cell constitutes an important regulator of $B$ cell development and physiology ${ }^{44}$, and was shown to be critical for the mast cell-induced proliferation and differentiation of both naïve and activated B cells in vitro ${ }^{45}$.

The relevance of IL- 6 in PAH is underscored by several individual case reports in which $\mathrm{PAH}$ patients received treatment with the anti-IL-6-receptor antibody tocilizumab which consistently resulted in improved clinical and hemodynamic parameters ${ }^{46-48}$. While these data support an important role for IL-6 in the pathogenesis of PAH, it remains unclear whether IL-6 is the only mediator by which mast cells may regulate $B$ cell activation and differentiation, and the subsequent generation of germinal centers, somatic hypermutations, affinity maturation of immunoglobins and plasma cell differentiation that will ultimately result in autoantibody production and autoimmunity ${ }^{49}$. To this end, Fernando and colleagues recently reported that endotracheal administration of an adenoviral vector expressing mouse oncostatin M (OSM) promotes B cell activation and BALT formation independent of IL- $6^{50}$. Notably, OSM is also, albeit not exclusively, secreted by mast cells ${ }^{51}$ and upregulated in the bronchoalveolar lavage fluid of patients with idiopathic pulmonary fibrosis and scleroderma or in plasma of PAH patients ${ }^{52,53}$, suggesting that mast cells may regulate adaptive (auto-)immunity and BALT formation via different pathways in $\mathrm{PH}$. The relevance of the ensuing autoimmune response is stressed by a series of experimental and clinical studies which detected an abundance of autoantibodies in plasma of PAH patients ${ }^{54}$, demonstrated that adoptive transfer of autoantibodies into naïve rats is sufficient to induce $\mathrm{PAH}^{37}$, and showed that B-cell depletion by the anti-CD20 antibody rituximab or B cell deficiency in $\mathrm{JH}$-KO rats prevented the development of experimental PAH and lung vascular remodeling in various animal models ${ }^{38,55}$. Notably, rituximab is presently in clinical trial for the treatment of PAH associated with connective tissue diseases such as systemic sclerosis (ClinicalTrials.gov Identifier: NCT01086540).

Last but not the least, mast cells may also be involved in the regulation of another main component of the adaptive immune system, namely $\mathrm{T}$ cells. Mast cells are now recognized to induce $\mathrm{T}$ cell activation, recruitment, proliferation, and cytokine secretion in an antigendependent manner ${ }^{56}$. This notion is consistent with the fact that T cell numbers are increased in BALT of PH lung tissue ${ }^{24}$, yet decreased by treatment with an anti-IL-6 antibody or in mast cell-deficient $W s / W s$ rats, respectively ${ }^{37,38}$. Conversely, mast cells are able to suppress regulatory $\mathrm{T}$ cells (Tregs) which have been reported to protect against hypoxiainduced PAH in mice ${ }^{57}$. The beneficial effect of Tregs in PH was particularly evident in a previous study in athymic rats in that the development of lung vascular remodelling and PH in response to the VEGF receptor antagonist SU5416 was attenuated in animals that had been reconstituted with $\mathrm{CD}^{+} \mathrm{CD} 25^{+} \mathrm{T}$ regs ${ }^{58}$. Although Tregs have been found to prevent BALT formation in LPS-induced inflamed lungs ${ }^{59}$, it presently remains unclear whether mast cells regulate BALT formation by promoting $\mathrm{T}$ cell proliferation or suppression of Tregs, respectively.

Taken together, a considerable body of experimental studies and clinical data have implicated an important role for mast cells in the pathogenesis of PH. Mast cells may act via several independent or, potentially, parallel mechanisms ranging from the release of the biogenic amine mediators histamine and serotonin, via secretion of the mast cell specific enzymes tryptase and chymase, to the regulation of adaptive immune responses and autoimmunity in $\mathrm{PH}$ (Figure 1). In the future, a better understanding of the molecular mechanisms by which mast cells promote lung vascular remodeling may provide for novel strategies to inhibit or even reverse $\mathrm{PH}$ development and pulmonary vascular remodeling. Such understanding may be fostered e.g. by studies aimed at deciphering the mechanisms of mast cell recruitment to the lung in $\mathrm{PH}$, of individual mast cell-derived mediators such as e.g. serotonin, or by functional screening of autoantibodies in serum of $\mathrm{PH}$ patients. In the meantime, commercially available overthe-counter drugs for mast cell stabilization may present an easily implementable and testable approach for an immuno-targeted treatment strategy in $\mathrm{PH}$ disease. 


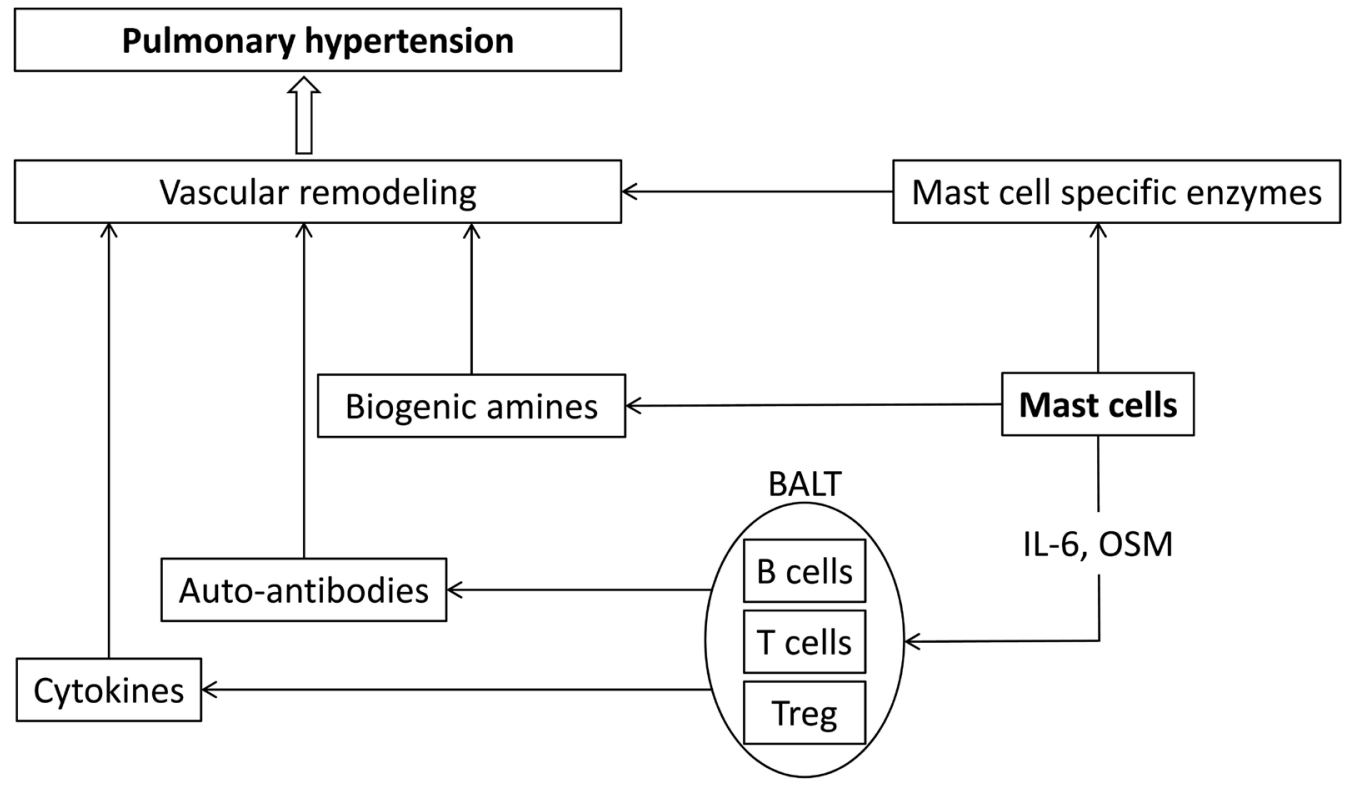

\author{
$B A L T$, bronchus-associated tertiary lymphoid tissue \\ OSM, oncostatin $M$ \\ Treg, regulatory $T$ cells
}

Figure 1: Schematic representation of the proposed mechanisms by which mast cells may promote lung vascular remodeling and hence, pulmonary hypertension. Specifically, mast cells may exert their effects via three different routes: i) release of biogenic amines such as histamine or serotonin; ii) secretion of mast cell specific enzymes including tryptase and chymase; and iii) formation of bronchus-associated tertiary lymphoid tissue (BALT) via release of interleukin- 6 like cytokines. BALTs consist of B cells, T cells, and regulatory $T$ cells (Tregs) and may promote lung vascular remodeling via the release of auto-antibodies and proliferation and/or hypertrophy stimulating cytokines.

\section{References}

1. Gomberg-Maitland M, Dufton C, Oudiz RJ, et al. Compelling evidence of long-term outcomes in pulmonary arterial hypertension? A clinical perspective. J Am Coll Cardiol. 2011; 57(9): 1053-1061.

2. Simonneau G, Gatzoulis MA, Adatia I, et al. Updated clinica classification of pulmonary hypertension. J Am Coll Cardiol. 2013; 62(25 Suppl): D34-41.

3. Almodovar S, Cicalini S, Petrosillo N, et al. Pulmonary hypertension associated with HIV infection: pulmonary vascular disease: the global perspective. Chest. 2010; 137(6 Suppl): 6S-12S.

4. Goldberg A. Pulmonary arterial hypertension in connective tissue diseases. Cardiology in review. 2010; 18(2): 85-88.

5. Rabinovitch $M$, Guignabert $\mathrm{C}$, Humbert $\mathrm{M}$, et al. Inflammation and immunity in the pathogenesis of pulmonary arterial hypertension. Circ Res. 2014; 115(1): 165-175.

6. Savai R, Pullamsetti SS, Kolbe J, et al. Immune and inflammatory cell involvement in the pathology of idiopathic pulmonary arterial hypertension. Am J Respir Crit Care Med. 2012; 186(9): 897-908.

7. Groth $A$, Vrugt B, Brock M, et al. Inflammatory cytokines in pulmonary hypertension. Respir Res. 2014; 15(1): 47.

8. Tuder RM, Stacher E, Robinson J, et al. Pathology of pulmonary hypertension. Clin Chest Med. 2013; 34(4): 639-650.

9. Meloche J, Renard S, Provencher S, et al. Anti-inflammatory and immunosuppressive agents in PAH. Handb Exp Pharmacol. 2013; 218: 437-476.

10. Beiträge EP. zur Kenntnis der granulierten Bindegewebszellen und der eosinophilen Leukozyten. Arch Anat Physiol. 1879; 3: 166-169.
11. Heath D, Trueman T,Sukonthamarn P. Pulmonary mast cells in mitral stenosis. Cardiovascular research. 1969; 3(4): 467-471.

12. Heath D,Yacoub M. Lung mast cells in plexogenic pulmonary arteriopathy. Journal of clinical pathology. 1991; 44(12): 1003-1006.

13. Mitani Y, Ueda M, Maruyama K, et al. Mast cell chymase in pulmonary hypertension. Thorax. 1999; 54(1): 88-90.

14. Hamada $\mathrm{H}$, Terai M, Kimura $\mathrm{H}$, et al. Increased expression of mast cell chymase in the lungs of patients with congenital heart disease associated with early pulmonary vascular disease. Am J Respir Crit Care Med. 1999; 160(4): 1303-1308.

15. Vaszar LT, Nishimura T, Storey JD, et al. Longitudinal transcriptional analysis of developing neointimal vascular occlusion and pulmonary hypertension in rats. Physiol Genomics. 2004; 17(2): 150-156.

16. Kay JM, Waymire JC,Grover RF. Lung mast cell hyperplasia and pulmonary histamine-forming capacity in hypoxic rats. The American journal of physiology. 1974; 226(1): 178-184.

17. Tozzi CA, Thakker-Varia S, Yu SY, et al. Mast cell collagenase correlates with regression of pulmonary vascular remodeling in the rat. Am J Respir Cell Mol Biol. 1998; 18(4): 497-510.

18. Tucker A, McMurtry IF, Alexander AF, et al. Lung mast cell density and distribution in chronically hypoxic animals. Journal of applied physiology: respiratory, environmental and exercise physiology. 1977; 42(2): 174-178.

19. Williams A, Heath D, Kay JM, et al. Lung mast cells in rats exposed to acute hypoxia, and chronic hypoxia with recovery. Thorax. 1977; 32(3): 287-295.

20. van Albada ME, Bartelds B, Wijnberg H, et al. Gene expression profile in flow-associated pulmonary arterial hypertension with neointimal 
lesions. American journal of physiology Lung cellular and molecular physiology. 2010; 298(4): 483-491.

21. Hoffmann J, Yin J, Kukucka M, et al. Mast cells promote lung vascular remodelling in pulmonary hypertension. Eur Respir J. 2011; 37(6): 1400-1410.

22. Gilfillan AM,Rivera J. The tyrosine kinase network regulating mast cell activation. Immunol Rev. 2009; 228(1): 149-169.

23. Bartelds B, van Loon RL, MohauptS, etal. Mast cell inhibition improves pulmonary vascular remodeling in pulmonary hypertension. Chest. 2012; 141(3): 651-660.

24. Dahal BK, Kosanovic D, Kaulen C, et al. Involvement of mast cells in monocrotaline-induced pulmonary hypertension in rats. Respir Res. 2011; 12: 60.

25. Banasova A, Maxova $\mathrm{H}$, Hampl V, et al. Prevention of mast cell degranulation by disodium cromoglycate attenuates the development of hypoxic pulmonary hypertension in rats exposed to chronic hypoxia. Respiration. 2008; 76(1): 102-107.

26. Farha S, Sharp J, Asosingh K, et al. Mast cell number, phenotype, and function in human pulmonary arterial hypertension. Pulm Circ. 2012; 2(2): 220-228.

27. Doggrell SA,Wanstall JC. Vascular chymase: pathophysiological role and therapeutic potential of inhibition. Cardiovascular research. 2004; 61(4): 653-662.

28. Kosanovic D, Luitel H, Dahal BK, et al. Chymase: a multifunctional player in pulmonary hypertension associated with lung fibrosis. Eur Respir J. 2015; 46(4): 1084-1094.

29. Riley DJ, Thakker-Varia S, Wilson FJ, et al. Role of proteolysis and apoptosis in regression of pulmonary vascular remodeling. Physiol Res. 2000; 49(5): 577-585.

30. Kosanovic D, Dahal BK, Peters DM, et al. Histological characterization of mast cell chymase in patients with pulmonary hypertension and chronic obstructive pulmonary disease. Pulm Circ. 2014; 4(1): 128-136.

31. Farha S, Dweik R, Rahaghi F, et al. Imatinib in pulmonary arterial hypertension: c-Kit inhibition. Pulm Circ. 2014; 4(3): 452-455.

32. Kwapiszewska G, Markart P, Dahal BK, et al. PAR-2 inhibition reverses experimental pulmonary hypertension. Circ Res. 2012; 110(9): 11791191.

33. Tchougounova E, Lundequist A, Fajardo I, et al. A key role for mast cell chymase in the activation of pro-matrix metalloprotease- 9 and promatrix metalloprotease-2. J Biol Chem. 2005; 280(10): 9291-9296.

34. Grigoryev DN, Mathai SC, Fisher MR, et al. Identification of candidate genes in scleroderma-related pulmonary arterial hypertension. Transl Res. 2008; 151(4): 197-207.

35. Wernersson S,Pejler G. Mast cell secretory granules: armed for battle. Nat Rev Immunol. 2014; 14(7): 478-494.

36. Perros F, Dorfmuller P, Montani D, et al. Pulmonary lymphoid neogenesis in idiopathic pulmonary arterial hypertension. Am J Respir Crit Care Med. 2012; 185(3): 311-321.

37. Colvin KL, Cripe PJ, Ivy DD, et al. Bronchus-associated lymphoid tissue in pulmonary hypertension produces pathologic autoantibodies. Am J Respir Crit Care Med. 2013; 188(9): 1126-1136.

38. Breitling S, Hui Z, Zabini D, et al. The mast cell-B cell axis in lung vascular remodeling and pulmonary hypertension. American journal of physiology Lung cellular and molecular physiology. 2017; 312(5): 710-721.

39. Humbert M, Monti G, Brenot F, et al. Increased interleukin-1 and interleukin-6 serum concentrations in severe primary pulmonary hypertension. Am J Respir Crit Care Med. 1995; 151(5): 1628-1631.

40. Steiner MK, Syrkina OL, Kolliputi N, et al. Interleukin-6 overexpression induces pulmonary hypertension. Circ Res. 2009; 104(2): 236-244.
41. Savale L, Tu L, Rideau D, et al. Impact of interleukin-6 on hypoxiainduced pulmonary hypertension and lung inflammation in mice. Respir Res. 2009; 10: 6.

42. Kishimoto T,Hirano T. Molecular regulation of B lymphocyte response. Annu Rev Immunol. 1988; 6: 485-512.

43. Hirano T. Interleukin- 6 and its relation to inflammation and disease. Clinical immunology and immunopathology. 1992; 62(1 Pt 2): S6065.

44. Galli SJ, Nakae S,Tsai M. Mast cells in the development of adaptive immune responses. Nat Immunol. 2005; 6(2): 135-142.

45. Merluzzi S, Frossi B, Gri G, et al. Mast cells enhance proliferation of B lymphocytes and drive their differentiation toward IgA-secreting plasma cells. Blood. 2010; 115(14): 2810-2817.

46. Furuya Y, Satoh T,Kuwana M. Interleukin-6 as a potential therapeutic target for pulmonary arterial hypertension. International journal of rheumatology. 2010; 2010: 720305.

47. Arita Y, Sakata Y, Sudo T, et al. The efficacy of tocilizumab in a patient with pulmonary arterial hypertension associated with Castleman's disease. Heart Vessels. 2010; 25(5): 444-447.

48. Taniguchi K, Shimazaki C, Fujimoto Y, et al. Tocilizumab is effective for pulmonary hypertension associated with multicentric Castleman's disease. Int J Hematol. 2009; 90(1): 99-102.

49. Cohen-Kaminsky S, Hautefort A, Price L, et al. Inflammation in pulmonary hypertension: what we know and what we could logically and safely target first. Drug discovery today. 2014; 19(8): 1251-1256.

50. Botelho FM, Rangel-Moreno J, Fritz D, et al. Pulmonary expression of oncostatin M (OSM) promotes inducible BALT formation independently of IL-6, despite a role for IL-6 in OSM-driven pulmonary inflammation. Journal of immunology (Baltimore, Md : 1950). 2013; 191(3): 1453-1464.

51. Salamon P, Shoham NG, Puxeddu I, et al. Human mast cells release oncostatin $\mathrm{M}$ on contact with activated $\mathrm{T}$ cells: possible biologic relevance. J Allergy Clin Immunol. 2008; 121(2): 448-455 e445.

52. Mozaffarian A, Brewer AW, Trueblood ES, et al. Mechanisms of oncostatin M-induced pulmonary inflammation and fibrosis. Journal of immunology (Baltimore, Md : 1950). 2008; 181(10): 7243-7253.

53. Weldy C, Bea F, Wijelath E, et al. Abstract 13449: Oncostatin M is Elevated in the Plasma of Patients With Pulmonary Arterial Hypertension, but Not in Patients With Ischemic Heart Disease or Dilated Cardiomyopathy: Insight Into Mechanisms in vitro. Circulation. 2011; 124(Suppl 21): A13449-A13449.

54. Becker MO, Kill A, Kutsche M, et al. Vascular receptor autoantibodies in pulmonary arterial hypertension associated with systemic sclerosis. Am J Respir Crit Care Med. 2014;190(7):808-817.

55. Mizuno S, Farkas L, Al Husseini A, et al. Severe pulmonary arterial hypertension induced by SU5416 and ovalbumin immunization. Am J Respir Cell Mol Biol. 2012;47(5):679-687.

56. Bulfone-Paus S,Bahri R. Mast Cells as Regulators of T Cell Responses. Frontiers in immunology. 2015; 6: 394.

57. Chu Y, Xiangli X,Xiao W. Regulatory $\mathrm{T}$ cells protect against hypoxiainduced pulmonary arterial hypertension in mice. Mol Med Rep.2015; 11(4): 3181-3187.

58. Nicolls MR, Mizuno S, Taraseviciene-Stewart L, et al. New models of pulmonary hypertension based on VEGF receptor blockade-induced endothelial cell apoptosis. Pulm Circ. 2012;2(4):434-442.

59. Foo SY, Zhang V, Lalwani A, et al. Regulatory T cells prevent inducible BALT formation by dampening neutrophilic inflammation. Journal of immunology (Baltimore, Md : 1950). 2015; 194(9): 4567-4576. 